\title{
A New Regimen of Complex Therapy for Aggressive Periodontitis
}

\author{
DOI: $10.17691 / \mathrm{stm} 2017.9 .4 .26$
}

Received June 8, 2017

E.S. Kachesova, PhD Student, Department of Therapeutic Dentistry;

E.A. Shevchenko, MD, DSc, Professor, Department of Pathological Physiology;

O.A. Uspenskaya, MD, DSc, Head of the Department of Therapeutic Dentistry

Nizhny Novgorod State Medical Academy, 10/1 Minin and Pozharsky Square, Nizhny Novgorod, 603005, Russian Federation

The aim of the investigation was to evaluate the efficacy of the new regimen of complex therapy for rapidly progressing periodontitis with the use of medications affecting bone tissue restoration and remodeling.

Materials and Methods. Treatment results were analyzed in 45 patients diagnosed with rapidly progressing periodontitis. The control group consisted of 12 practically healthy individuals. Metronidazole suspension was introduced into the periodontal pockets of patients in group 1, while patients of group 2 underwent introduction of Metronidazole and Aplun mixture in suspension. General treatment in both groups included administration of Tevabone. In patients of group 3, Metronidazole suspension was introduced in the periodontal pockets, while general treatment included the use of Calcemin.

Results. Clinical studies and biochemical parameters of the oral fluid in patients of group 2 evidenced rapid and sustained decrease in inflammation, earlier regeneration of the periodontal tissue and bone restoration as compared to groups 1 and 3 .

Conclusion. The proposed regimen of complex therapy for rapidly progressing periodontitis including locally used Aplun medication in addition to administration of Tevabone has demonstrated greater treatment efficacy as compared to conventional therapy.

Key words: rapidly progressing periodontitis; treatment of periodontitis; Aplun; Tevabone; biochemical parameters of the oral fluid.

Insufficient understanding of etiopathogenetic mechanisms of periodontitis resulting in ineffective treatment often leads to rapid aggravation of the disease and teeth loss, which underlies the search for more effective ways of treating this pathology [1].

Currently, complex therapy often includes drugs eliminating the adverse effects of the oral microflora, effectively removing the consequences of metabolic disorders in the periodontal tissues as well as improving life quality of patients with inflammatory periodontal diseases. For example, there have been demonstrated therapeutic effects of Metronidazole having antiprotozoal and antibacterial activity against anaerobic protozoa and anaerobic bacteria that cause periodontal disease [2]

In recent years, Aplun with antimicrobial activity has proved effective. It has an analgesic effect, prevents recurrent infection, promotes metabolism and tissue regeneration, which is important for treatment of periodontitis. The therapeutic effect of Aplun is determined by the presence of lanthanum in the formula. Lanthanum is a representative of the family of rareearth metals (lanthanides). Lanthanum ions are known to produce an anti-inflammatory effect, have greater affinity to phospholipids and "stabilize" cell membranes by blocking ion channels. The effect of lanthanides on inflammation is similar to that of corticosteroids. Dehydrating activity of the drug is 13.5 times higher than that of hypertonic $\mathrm{NaCl}$ solution, which provides intensive outflow of exudate from the wound into the bandage, reduces edema and infiltration of the wound edges. Lanthanides have antimicrobial activity, enhance phagocytic activity of leukocytes, provide rejection of necrotic tissue, promote cell proliferation, which leads to rapid healing of the wound surface [3, 4]. Aplun creates a protective membrane and can be used as a biological barrier with action time up to $8 \mathrm{~h}$ without impeding the oxygen access [5-7]. However, this drug has not been used for treatment of inflammatory periodontal diseases.

It has been established that systemic osteoporosis is one of the important factors predisposing to the development of generalized periodontitis and influencing its course. Despite the high degree of bone tissue mineralization, its constituent substances undergo constant regeneration and adaptive changes in response to changing conditions of functioning. The main "participants" of this process are the levels of calcium and phosphorus circulating in extracellular fluid and hormones regulating their metabolism. It has been shown [8] that changes in the jaw bone tissue are present in all cases when there are even small pathological

For contacts: Evgenia S. Kachesova, e-mail: kachesova-es@yandex.ru 
inflammatory changes of the oral mucosa. This suggests much greater pathogenetic relationship between inflammatory changes in the mucous membrane and changes in the osseous part of the periodontium. These changes are likely to occur simultaneously. Today, many new co-formulated drugs have been developed to treat systemic osteoporosis. In recent years, there has been successfully applied Tevabone combining two active ingredients: alendronic acid and alfacalcidol [9]. Alendronic acid inhibits the process of active bone tissue resorption, increases bone mineralization and improves bone quality characteristics. Alfacalcidol regulates calcium and phosphorus metabolism. It has not been used in periodontology either. Therefore, it was decided to include both of the mentioned drugs (Aplun and Tevabone) in complex treatment of periodontitis [10].

The aim of the study was to evaluate the efficacy of the new regimen of complex therapy for rapidly progressing periodontitis with the use of drugs affecting bone tissue restoration and remodeling.

Materials and Methods. The study was carried out in the dental clinic of Nizhny Novgorod State Medical Academy. The study involved 45 patients with the diagnosis of rapidly progressing periodontitis who underwent examination and treatment. The control group consisted of 12 practically healthy individuals.

The criterion for inclusion of patients in the study was age between 25 and 35 years. Exclusion criteria were the presence of severe somatic pathology (celiac disease, diabetes, kidney and liver diseases) at decompensation stage, immunodeficiency, pregnancy, lactation, postmenopausal women, drug and alcohol abuse, refusal to participate in the study.

The study complies with the Declaration of Helsinki (the Declaration was passed in June 1964, Helsinki, Finland and revised in October 2000, Edinburgh, Scotland) and was performed following approval by the Ethics Committee of Nizhny Novgorod State Medical Academy. Written informed consent was obtained from every patient.

All patients with rapidly progressing periodontitis received etiopathogenetic treatment, which included oral hygiene control, oral cavity sanation, splinting of loose teeth when indicated, consultation of an orthopedist to assess the condition of dental prostheses existing in the oral cavity, selective grinding, rational prosthodontic treatment, consultation of an orthodontist to eliminate the existing malocclusion, consultation of a dental surgeon to eliminate anomalies of labial and lingual frenulum attachment, drawing up a plan of surgical treatment when indicated, treatment and dynamic observation by a doctor specializing in the appropriate field in case of concomitant pathology.

Professional oral hygiene consisted of removing subgingival dental deposits using ultrasonic system Piezon-Master (EMS, Switzerland) and the Vector system (Durr Dental, Germany) and medicament treatment with $0.2 \%$ chlorhexidine solution.
Depending on further local treatment, the patients were divided into three groups.

In group $1(\mathrm{n}=15)$, Metronidazole suspension was introduced into the periodontal pockets of patients; general treatment included administration of Tevabone for 2 months.

The patients of group 2 (the main group, $n=15$ ) underwent local treatment according to the proposed regimen: mixture in the form of suspension prepared ex tempore and containing $250 \mathrm{mg}$ of 2-methyl-5nitro-1H-imidazole-1-ethanol (1 Metronidazole tablet) and 5-7 drops of liquid Aplun medication (a complex compound of lanthanum nitrate and tri-ethylene glycol in glycerol) was introduced into the periodontal pockets; these procedures were performed daily for 7-10 days; general treatment included Tevabone for 2 months.

Patients of group $3 \quad(n=15)$ also received local treatment according to the proposed regimen and general treatment included the use of Calcemin for 2 months.

Follow-up monitoring was carried out once in 10 days during the first three months after complex individualized treatment, then once every 3 months during 1 year for oral hygiene correction.

Florida Probe software (USA) was applied to determine the degree of periodontal tissue destruction, to reveal the disease dynamics in treatment process, the patient's treatment motivation and to increase personal interest in maintaining proper oral hygiene. After examination, each patient received a printout of examination results.

To assess therapy efficacy, the following clinical indices were used: papillary-marginal-alveolar (PMA) index in the modification of Parma (1960) and comprehensive periodontal index (CPI), proposed by Leus (1988). The biochemical parameters of the oral fluid (the content of calcium, phosphorus and alkaline phosphatase) were also estimated.

Results and Discussion. The day following the beginning of treatment, the patients of group 2 (the main) observed a marked decrease in bleeding, some patients reporting its complete absence (Figures 1,2). Florida Probe software data showed periodontal pocket depth reduction by day 7 of treatment, which was associated with antiedematous, anti-inflammatory and antimicrobial action of the drugs. There was also noted a significant decrease in teeth mobility which was the most marked by day 30 of treatment.

Just on day 3 of treatment, the patients in groups 2 and 3 showed a significant decrease in inflammation: PMA index decreased almost 2 times (in group 2 from $65.7 \pm 1.7$ to $33.2 \pm 1.7 \% ; p<0.001$; in group 3 from $62.9 \pm 1.6$ to $30.6 \pm 1.7 \% ; p<0.001$ ), whereas in group $1-$ by 1.13 times (Figure 3 ).

After 7 days, this index was close to the control $(11.6 \pm 1.8 \%)$ in groups where Aplun was used (15.4 $\pm 1.6 \%$ in group 2, $16.1 \pm 1.4 \%$ in group 3$)$. In group 2, PMA level remained unchanged throughout 


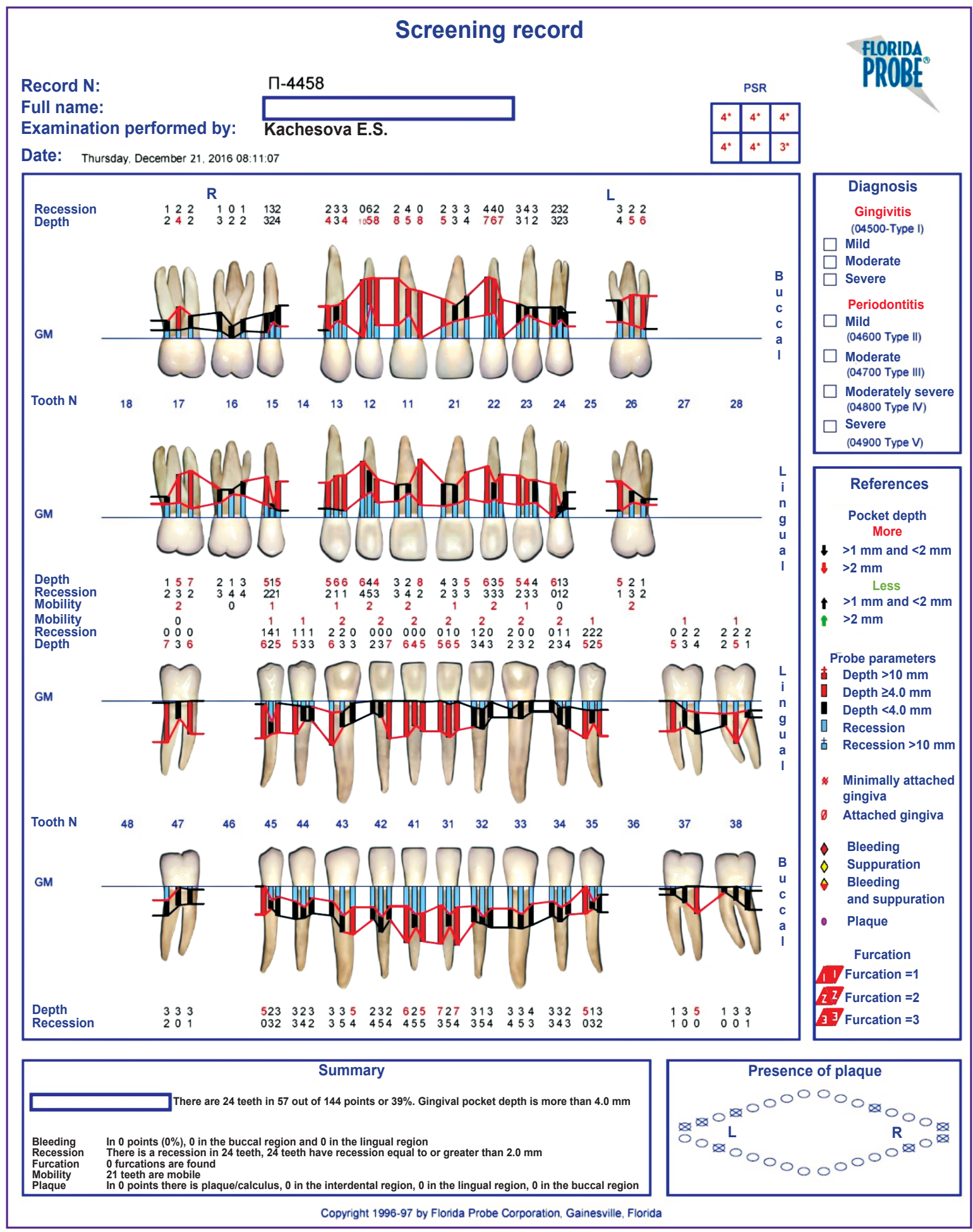

Figure 1. Screening record of patient T. from group 2 with the use of Florida Probe software before treatment

the observation period, while it tended to increase in group 3. In group 1, PMA index also decreased after 7 days $(24.1 \pm 1.7 \%)$ and came closer to the control, but was statistically significantly higher $(p<0.001)$ than in groups 2 and 3 . The lowest value of this index was recorded in group 1 after 1 month $(20.8 \pm 1.7 \%)$, but later it was found to be increasing. In 6 and 12 months, this indicator values were statistically significantly higher $(p<0.001)$ in group $1(28.5 \pm 1.7$ and $27.2 \pm 1.6 \%$, respectively) than in group $2(15.8 \pm 1.6$ and $13.7 \pm 1.7 \%)$.

The obtained results confirm the anti-inflammatory and antimicrobial activity of Aplun, which is particularly 


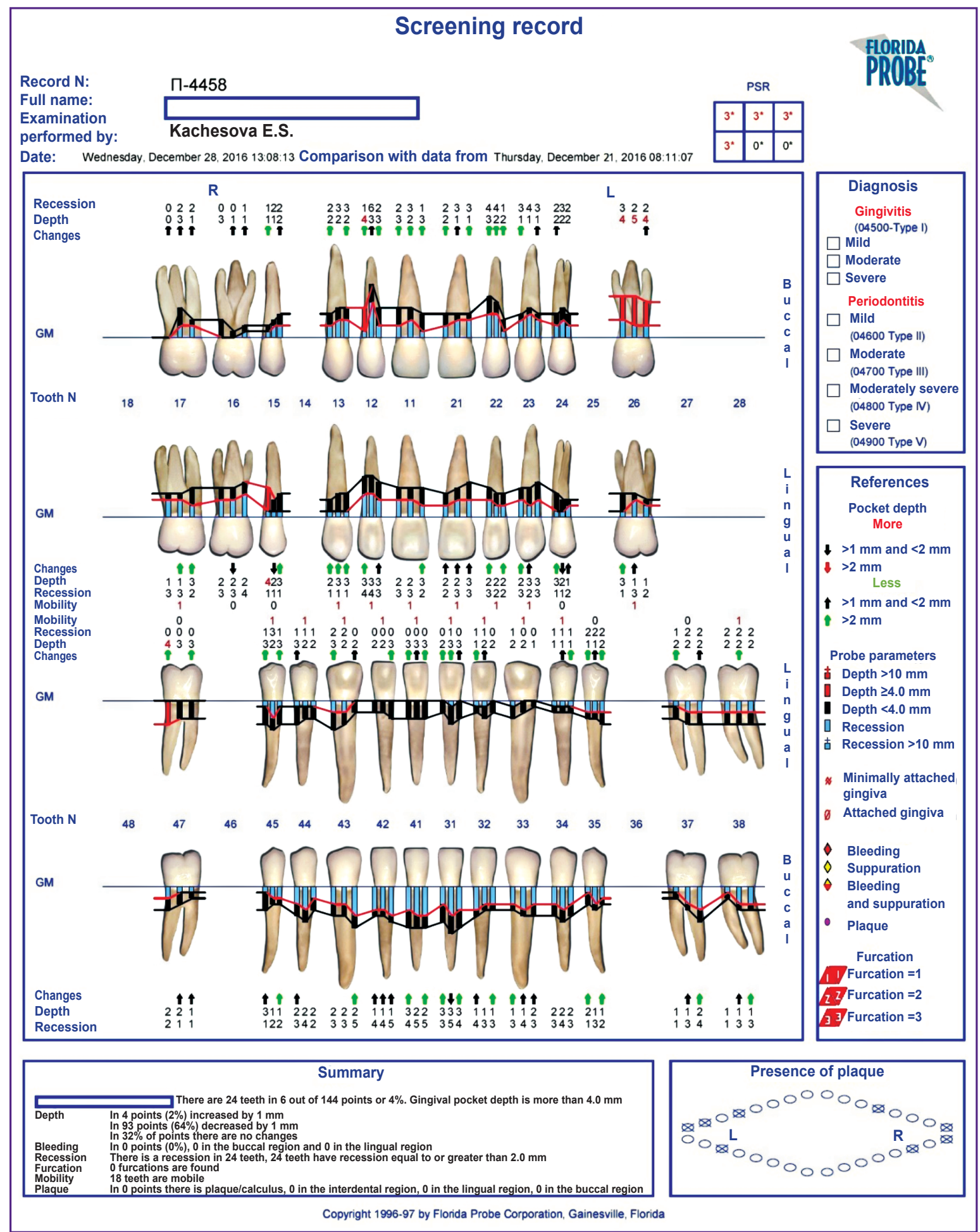

Figure 2. Screening record of patient T. from group 2 with the use of Florida Probe software on day 7 of treatment

pronounced when it is used in complex with Tevabone.

The similar pattern was observed when the dynamics of CPI was studied (Figure 4).

Just in 3 days, CPI statistically significantly decreased $(p<0.001)$ in groups where Aplun was used for treatment as compared to the values before treatment $(3.2 \pm 0.2$ vs $4.5 \pm 0.2$ in group 2 and $3.3 \pm 0.2$ vs $4.6 \pm 0.2$ in group 3 ), while in group 1 where Aplun was not used, the index remained almost unchanged. $\mathrm{CPI}$ decrease was observed in group 1 only on day 7 of treatment $(3.8 \pm 0.2)$, 


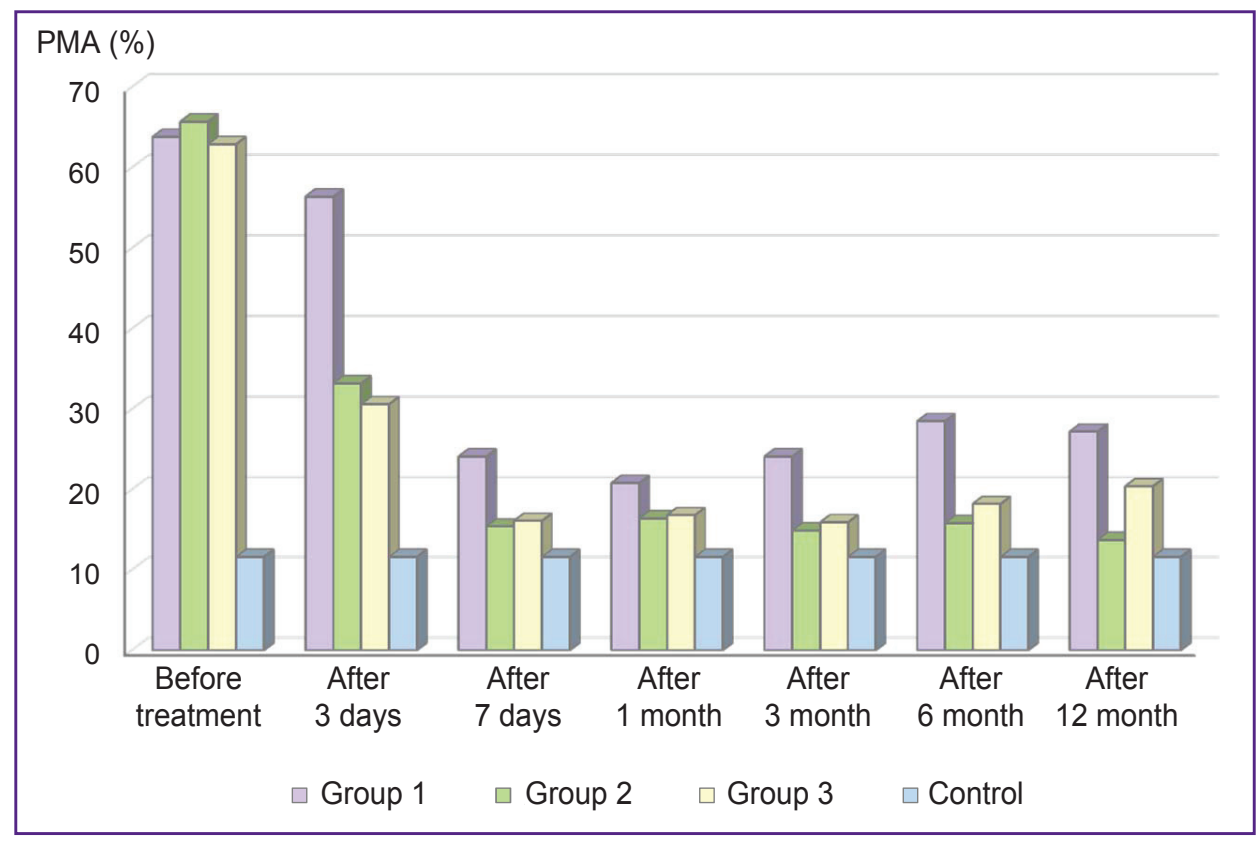

Figure 3. Dynamics of PMA index in treatment of patients with rapidly progressing periodontitis at different treatment regimens

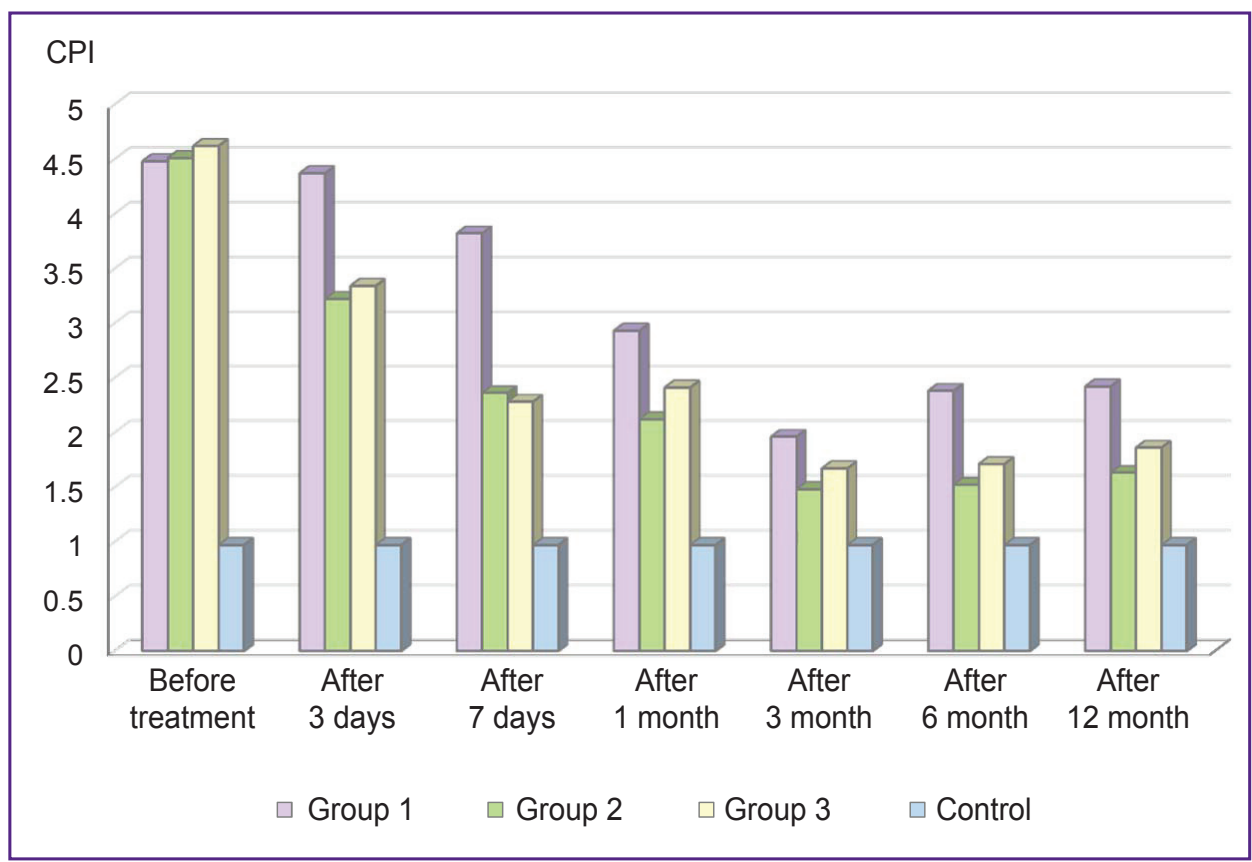

Figure 4. Dynamics of $\mathrm{CPI}$ in treatment of patients with rapidly progressing periodontitis at different treatment regimens

though it remained statistically significantly higher $(p<0.001)$ than in groups 2 and $3(2.4 \pm 0.2$ and $2.3 \pm 0.2)$. The minimum values of periodontal index were registered in all groups after 3 months of treatment, later they tended to increase slightly. However, in patients of group 1, the values were statistically significantly higher $(p<0.01)$ after 6 and 12 months $(2.4 \pm 0.2$ and $2.4 \pm 0.2$, respectively) than in group $2(1.5 \pm 0.2$ and $1.6 \pm 0.2$, respectively).
Thus, clinical parameters in patients of group 2 showed more rapid restoration of periodontal tissues, this effect remaining longer. Therefore, complex treatment of rapidly progressing periodontitis with the use of Aplun and Tevabone was the most effective.

In the process of therapy, the biochemical parameters of the oral fluid were also estimated. The dynamics of calcium level is shown in Figure 5. 


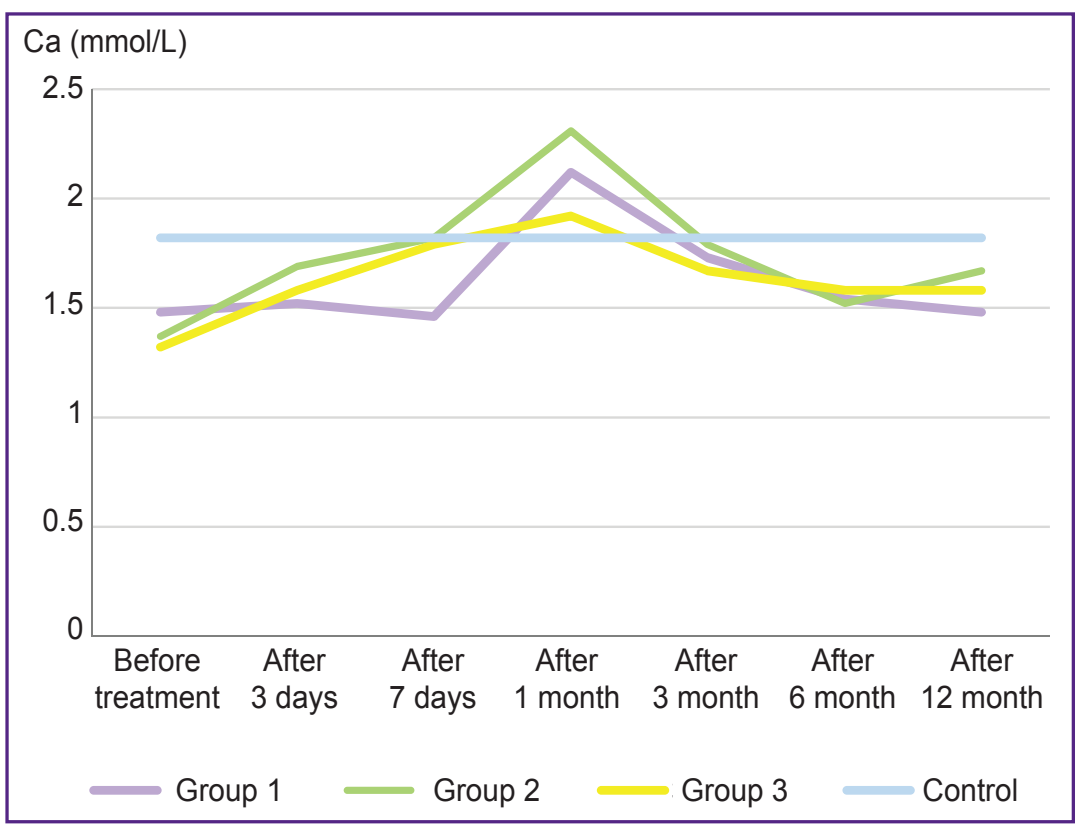

Figure 5. Dynamics of calcium level in the oral fluid of patients with rapidly progressing periodontitis at different treatment regimens

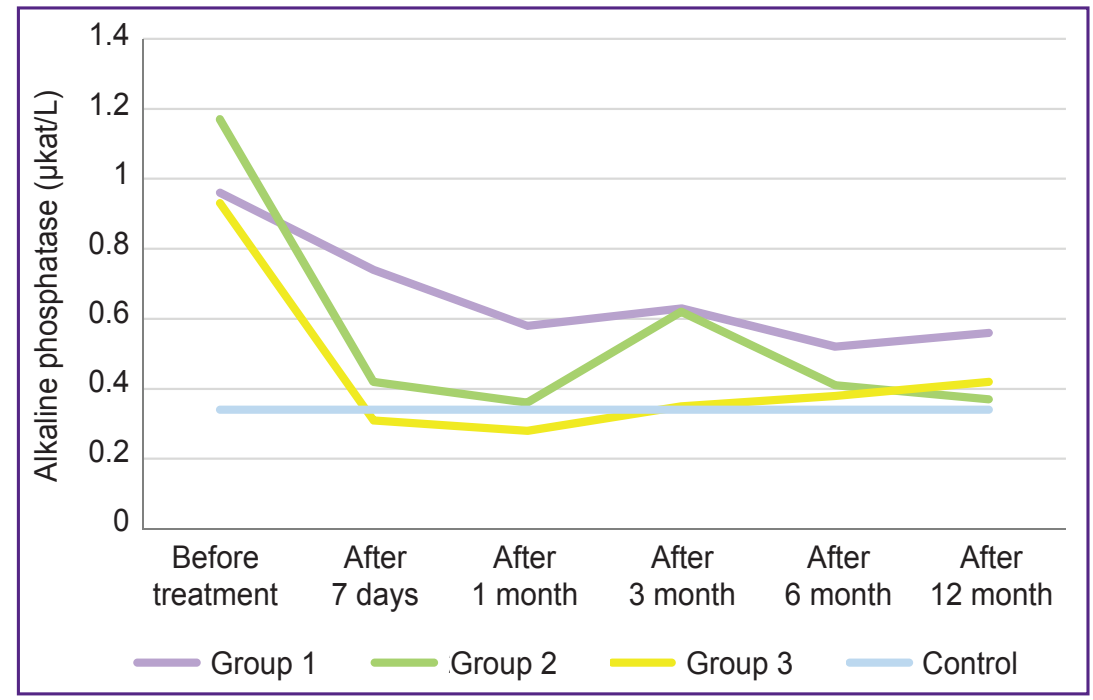

Figure 6. Dynamics of alkaline phosphatase level in the oral fluid of patients with rapidly progressing periodontitis at different treatment regimens

As it is shown in the diagrams, calcium levels before treatment were significantly lower in all groups $(1.48 \pm 0.07 \mathrm{mmol} / \mathrm{L} ; \quad p<0.01$ for group $1 ; 1.37 \pm 0.08 \mathrm{mmol} / \mathrm{L} ; \mathrm{p}<0.001$ for group 2 ; $1.32 \pm 0.07 \mathrm{mmol} / \mathrm{L} ; \mathrm{p}<0.001$ for group 3$)$ than in the control $(1.82 \pm 0.08 \mathrm{mmol} / \mathrm{L})$.

Treatment of rapidly progressing periodontitis with the use of Aplun led to increased Ca levels in these groups just after 7 days $(1.82 \pm 0.08 \mathrm{mmol} / \mathrm{L}$ in group 2 and $1.79 \pm 0.08 \mathrm{mmol} / \mathrm{L}$ in group 3$)$, which was statistically significantly $(p<0.01)$ different from these values in the same groups before treatment. In group 1, almost no changes in this parameter were observed after 7 days of treatment $(1.46 \pm 0.07 \mathrm{mmol} / \mathrm{L}$ vs $1.48 \pm 0.07 \mathrm{mmol} / \mathrm{L}$ before treatment), $\mathrm{Ca}$ levels were significantly lower than in groups 2 and 3 . This can be explained by activation of the organism's reserve forces due to local effect of Aplun, promoting bone tissue restructuring and regeneration of damaged periodontal tissues.

After 1 month, there was a statistically significant increase in calcium levels in groups where treatment included Tevabone $(2.12 \pm 0.08 \mathrm{mmol} / \mathrm{L}$ for group 1 and $2.31 \pm 0.08 \mathrm{mmol} / \mathrm{L}$ for group 2 ), but it proved to decrease significantly $(1.73 \pm 0.08 \mathrm{mmol} / \mathrm{L}$ for group 1 and $1.79 \pm 0.07 \mathrm{mmol} / \mathrm{L}$ for group 2 ; $p<0.001)$ in 3 months. This fact is explained by the ability of Tevabone to enhance calcium absorption within 2 months of intake followed by active osteogenesis (after 3 months), which is accompanied by a decrease in salivary calcium content and its involvement in bone tissue mineralization. A similar trend was observed in group 3 where Calcemin was used, but the data are not statistically significant.

Changes of alkaline phosphatase activity in different periods of treatment are presented in Figure 6.

Increased salivary levels of alkaline phosphatase in patients with rapidly progressing periodontitis before treatment $(0.96 \pm 0.03 \mu \mathrm{kat} / \mathrm{L}$ for group $1,1.17 \pm 0.03 \mu \mathrm{kat} / \mathrm{L}$ for group 2 and $0.93 \pm 0.03 \mu \mathrm{kat} / \mathrm{L}$ for group 3 ; $\mathrm{p}<0.001)$ compared to the control $(0.34 \pm 0.02 \mu \mathrm{kat} / \mathrm{L})$ can be attributed to the presence of inflammatory process in periodontal tissues. In study groups 2 and 3 , alkaline phosphatase activity was close to the control just on day 7 of treatment and equaled $0.42 \pm 0.03 \mu \mathrm{kat} / \mathrm{L}$ and $0.31 \pm 0.03 \mu \mathrm{kat} / \mathrm{L}$, respectively, which was statistically significantly $(p<0.001)$ lower than in group $1(0.74 \pm 0.03 \mu \mathrm{kat} / \mathrm{L})$.

Dynamics of alkaline phosphatase activity shown in Figure 6 demonstrates decline in its oral fluid levels after 1 month of observation, however, the parameters in groups 2 and 3 remain statistically significantly lower $(p<0.01)$ than in group $1(0.58 \pm 0.03 \mu \mathrm{kat} / \mathrm{L})$. The revealed changes indicate more rapid regression of the inflammatory process and more sustainable results when local treatment regimen included Aplun as compared to the conventional regimen.

By the $3^{\text {rd }}$ month of treatment, a significant increase 
in alkaline phosphatase levels $(0.58 \pm 0.033 \mu \mathrm{kat} / \mathrm{L}$; $p<0.001)$ was registered in group 2 , a tendency to increase in this parameter also being observed in groups 1 and 3 . However, the values in group 2 were found to be statistically significantly higher $(0.62 \pm 0.03 \mu \mathrm{kat} / \mathrm{L}$; $p<0.001)$ than in group $3(0.35 \pm 0.03 \mu k a t / L)$. Clinically, inflammation declined in group 2 within 3 months (see Figure 3), therefore, we attribute increase in alkaline phosphatase levels during this period to the increase in functional activity of osteoblasts and bone tissue mineralization due to administration of Tevabone in complex therapy for rapidly progressing periodontitis.

In 6 months, a decrease in alkaline phosphatase levels $(0.41 \pm 0.03 \mu \mathrm{kat} / \mathrm{L} ; \mathrm{p}<0.001)$ and approximation of this parameter to the control values was registered in group 2. This trend remained even in month 12 of followup. These changes are likely to occur due to calcium and phosphorus precipitation on collagen with the formation of primary crystallization centers, stabilization of regeneration processes, their course being less intensive.

Thus, biochemical parameters of the oral fluid in patients of group 2 evidence more rapid and sustainable decline in inflammatory processes, periodontal tissue regeneration and bone tissue restoration as compared to groups 1 and 3 .

Conclusion. The results of biochemical analysis and clinical data allow making a conclusion about the efficacy of the proposed treatment regimen including locally used Aplun in addition to administration of Tevabone in complex therapy of rapidly progressing periodontitis.

Study Funding and Conflict of Interests. This study was not supported by any financial sources and the authors have no conflict of interests to disclose.

\section{References}

1. Lukinykh L.M., Kruglova N.V. Chronic generalized periodontitis. Part I. Modern view of etiology and pathogenesis. Sovremennye tehnologii v medicine 2011; 1: 123-125.
2. Lukinykh L.M., Kruglova N.V. Case of a chronic generalized parodontitis conservative treatment with a use of new technologies. Sovremennye tehnologii v medicine 2010; 4: 145-147.

3. Blatun L.A., Mitish V.A., Terekhova R.P., Grishina I.A., Alekseev A.A., Kirienko A.I., Bogdanets L.I., Titkova Yu.S., Novozhilov A.A., Smirnov S.V., Borisov V.S., Palchun V.T., Polyakova T.S., Luchikhin L.A., Bardychev M.S., Fradkin V.G., Teterin K.A., Yarustovskaya O.V., Markina L.P., Alisultanova L.S., Abramov I.S., Butivshchenko I.A., Novikov V.A., Zinger V.G., Petryakina L.G., Bystritskaya T.F., Grebenyuk V.N., Stepchenkova T.I., Chernakova N.N., Mokrousov M.S., Zakharchenko N.N., Madzhid Kh.Kh., Poleshchuk I.P., Gorshkov A.P., Vorotyagina N.A., Vasnetsova O.A. Eplan (ointment, solution) is a new medication for the topical treatment of skin and soft tissue infections at multidisciplinary hospital. Rany $i$ ranevye infektsii 2014; 1: 13-21.

4. Uspenskaya O.A. Dynamics of indices of local immune system of oral cavity in the case of patients with chronic recurring aphthous stomatitis and urinogenital infection. Meditsinskiy al'manakh 2015; 3(38): 196-198.

5. Uspenskaya O.A., Shevchenko E.A. A study of the influence of a range of medical products on the clinical course of local inflammatory processes in the buccal cavity and urogenital tract at pregnant women with CPI. Fundamental'nye issledovaniya 2015; 1-4: 837-839.

6. Uspenskaya O.A., Shevchenko E.A., Boltenko S.A. Modern methods of treatment of chronic recurrent aphthous stomatitis in women with urogenital infection and without. Sovremennye problemy nauki i obrazovaniya 2015; 1-1: 1324.

7. Uspenskaya O.A. The use of Atarax and Eplan in integrated treatment of chronic recurrent aphthous stomatitis. Universum: meditsina i farmakologiya 2015; 2(15): 4.

8. Shcherbich V.M., Moscovskiy S.N., Konev V.P., Sulimov A.F. Quality indices of jaw bone tissue in screening diagnostics of parodontal diseases. Saratovskiy nauchnomeditsinskiy zhurnal 2009; 5(4): 588-590.

9. Shvarts G.Ya. Tevabon - a new combination product for the treatment of osteoporosis. Russkiy meditsinskiy zhurnal 2011; 19(10): 623-631.

10. Uspenskaya O.A., Kachesova E.S. Method for treatment of fast progressing periodontitis. Patent RU 2628880. 2017. 